\title{
Residents' Attitudes towards the Residential Urban Forest in Metropolitan City: A Case Study from Bharatpur City in Nepal
}

\section{Yam Bahadur K.C. ${ }^{*}$ and Sagarika Sedhai ${ }^{1}$}

Abstract : Urban forests are critical element in ameliorating urban habitats and building sustainable cities. Local residents are the key players in maintaining greenery of the city as they collectively own majority of land in most cities. Therefore, they need to engage in planting and retaining trees on their properties in order to reach canopy cover in urban areas. The project surveyed 200 local residents in Bharatpur Metropolitan City to examine their attitude towards trees on their property on the basis of 'Affective', 'Behavioral' and 'Cognitive' ABC model of attitude. Results show that majority of the residents have positive attitude towards trees as they have high cognitive intention towards trees, and showed willingness to retain the existing trees and add more in future. However, very few are cognizant of the environmental values of trees. The most common positive effects of trees on their property are food, shade, and clean and fresh air. The most common negative effects are increase in bushes and weeds, wildlife hazards and risk of fall due to wind. Urban planners interested in influencing residents' decisions about urban trees need to work on public outreach. Residents need to be motivated and made aware of the long term and multifunctional benefits of trees for retaining the existing trees and planting more in their property. They should also, be made aware of the type of trees that are suitable for plantation on residential property in order to avoid the problems that can be created due to trees.

Key words: Urbanization, negative effects, positive effects of trees, cognitive intention, environmental values

K.C., Y.B., Sedhai, S. (2019): Residents' Attitudes towards the Residential Urban Forest in Metropolitan City: A Case Study from Bharatpur City in Nepal. Forestry: Journal of Institute of Forestry, Nepal. No. 16: page 72 to 85.

${ }^{1}$ Institute of Forestry, Tribhuvan University, Hetauda, Nepal.

*Corresponding author, email: ykc@iofhc.edu.np 


\section{Introduction}

The concept of urban forestry emerged worldwide in response to the adverse environmental effects due to increased urban population and infrastructure. In Nepal, the practice of urban forestry dates back to the Malla reign. A review of historical documents reveals that King Jayasthiti Malla (1380-1395 AD) issued an order to his officials and commoners to plant trees alongside walking streets and wells. Nepal government has emphasized urban forestry through its various programs, including 'Nepal Clean Environment Grand Expedition 2075 AD' and the 'Forest Decade Program (2014-2023), (Goutam 2018), the later promoting afforestation in public and private lands with the theme of 'one house: one tree, one village: one forest and one town: several parks'. Ongoing rapid and chaotic urbanization has brought about a wide range of challenges across the globe as more land is required to cater to the needs of growing population with a detrimental effect on forests and other green areas. Developing sustainable cities in such a way that all citizens can enjoy a high quality of life and environment will be one of the main challenges of our time. United Nations predicted that by 2050 about $64 \%$ of the developing world will be urbanized, and therefore, urban forestry has been recognized as an important part of urban life (UNDESA 2019).

Urban forest is the backbone of the green infrastructure, bridging rural and urban areas and ameliorating a city's environmental footprint (FAO 2016). FAO (2016) defined urban forest as a network or system comprising all woodlands, groups of trees, and individual trees located in urban and peri-urban areas; they include, therefore, forests, street trees, trees in parks and gardens, and trees in derelict corners. Urban trees have been reported to affect local and regional air quality by removing atmospheric pollutants and chemicals from the vegetation, altering urban microclimates by lowering temperatures through shading and evapo-transpiration, changing wind patterns, modifying boundary layer heights, and reducing building energy use and consequent emissions from power plants (Beckett et al. 2000). Urban trees also influence global climate change through direct removal of greenhouse gases from the atmosphere and by affecting emissions from energy production (McPherson et al. 1999). Trees on residential property, located in cities are part of urban forests. In order to increase canopy cover in urban areas, residents, who collectively own majority of the land in most cities, need to engage in planting and retaining trees on their property (Diley, Wolf 2013).

Nepal is one of the 10 least urbanized countries in the world. However, it is also one of the top 10 fastest urbanizing countries (Bakrania 2015), and it has invited several problems in human life and environment like pollution, flooding and social disorders (Nepali 2017). Considering the importance of urban greens for multiple social, economic, ecological and environmental benefits, Environment 
Friendly Local Governance Framework (2013) has emphasized to maintain green environment at household level with the recommendation to plant at least two trees in each household (MFALD 2019). However, the perspectives of residents towards private trees and their behavioral patterns regarding tree plantation, retention or removal on their property have not yet been studied. Therefore, this study intends to examine the residents' attitude and behavior, concerning all trees associated with their property, as residential tree planting behavior across an entire parcel is important to reach canopy cover goals.

\section{Materials and Methods}

\section{Study Area}

The study was conducted in Bharatpur Metropolitan City, Chitwan district, Province-3 of Nepal. It is the head quarter of Chitwan district, and is located at $27^{\circ} 41^{\prime} 0^{\prime \prime}$ North, $84^{\circ} 26^{\prime} 0^{\prime \prime}$ East. With an elevation of $208 \mathrm{~m}$, it is characterized by a humid sub-tropical climate. It is the fourth largest city of Nepal with an area of $433 \mathrm{~km}^{2}$, and is one of the fast growing cities with the population of 280,502 (Census 2015), where in-migration rate is higher from various parts of the country (Bharatpurmun.gov.np. 2019). The rapid population growth ultimately affects the existing green cover in the city due to increase in demand for land resources for settlements and development projects. Bharatpur provides a unique opportunity for studying the attitudes of local residents towards trees in response to continuing development during a period of rapid economic change in the country.

For the purpose of this study, ward number 10 and ward number 14 were selected on the basis of maximum variation sampling in order to comprehend wider aspects of city and residents (Figure 1).

Ward number 10 represents the core- urban part of the city whereas the other represents the sub-urban part. Ward number 10 spans over an area of $3.94 \mathrm{~km}^{2}$. It has 6477 households with 221,844 people. Similarly, ward number 14 spans over an area of $12.07 \mathrm{~km}^{2}$ and 2094 households with 8,521 people. These wards were classified into 'core-urban' and 'sub-urban' on the basis of population density and their proximity to the main part of the city. 


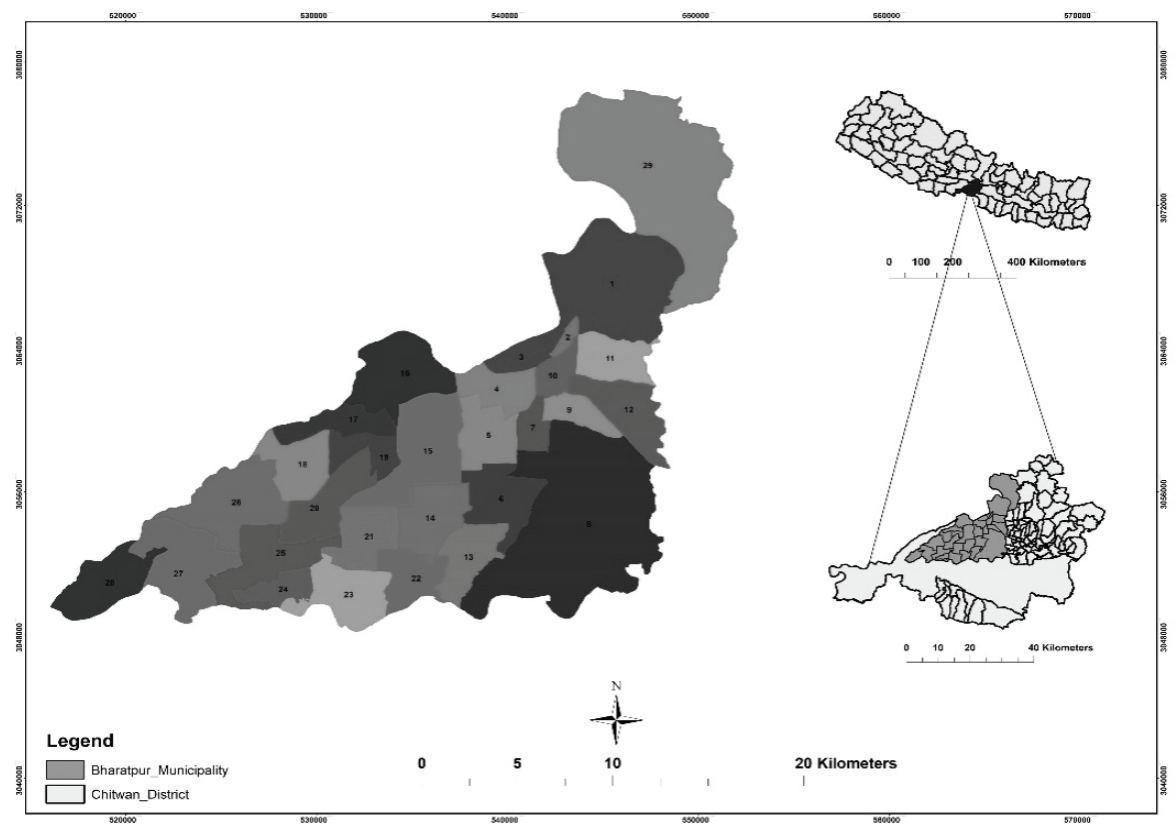

Figure1 : Location Map of the Study Area

\section{Methods}

\section{Data Collection}

Purposive sampling was conducted to document the residents' attitude towards residential trees. 100 residents each from ward number 10 and 14 were interviewed with semi-structured questionnaire. Purposive sampling was thought to be appropriate for this study due to: (a) large and unknown population size, (b) the study was aimed only at residents having trees on their property, and (c) time limitation.

The questionnaire was divided into two sections, the first section contains questions about socio-economic background of the respondents: gender, age, average family income, education, occupation, and landholdings; while the second part focused on their mental responses towards trees on their property which were based on ABC model of attitude (Jain 2014). Respondents were asked to indicate their response along a 5-point Likert Scale from strongly disagree to strongly agree to 10 statements about the significances of trees in order to study the residents' knowledge and beliefs about trees. Multiple choice questions were constructed to ascertain (i) reasons to plant trees in their residential property, (ii) effects of trees in their residential property, (iii) types of trees that are likely to be added by residents in future, and (iv) reasons for their intention to remove existing trees in future. Dichotomous questions were 
constructed to know their feelings towards trees on their property. Propensity questions were developed to study the behavioral intentions of residents regarding retention, addition in and removal of trees from their properties.

Households were identified on the basis of direct observation of presence of trees in the property. An approximate number of trees in each household, types of trees and their condition were also recorded through direct observation.

\section{Data Analysis}

The data was analyzed on the basis of the $A B C$ model of attitude in which 'Affective', 'Behavioral' and 'Cognitive' components of residents' attitude were measured (Jain 2014). The input for the data of residents' cognitive intention towards trees was the scores on the 5-point Likert scale where 'strongly disagree' was ranked ' 1 ' and 'strongly agree' was ranked ' 5 '. The input for the data about tree planting reasons, effects of trees in the respondents' properties and their feelings towards it, types of trees they want to add in future and reasons for the intention of removing existing trees was qualitative. A dummy (yes/no) variable for possible reply was created and coded it ' 1 ' if the respondent checked the box and ' 0 ' if they did not. Bipolar adjectives were used to assess the feelings of respondents towards trees on their property through semantic differential scale. The input for the data of likelihood of respondents to add or remove trees in future was scored on the 4-point Likert scale where 'definitely not' was ranked ' 1 ' and 'definitely yes' was ranked '4'. The data were analyzed using MS Excel 2010 and SPSS 16 both qualitatively and quantitatively and summarized in the form of tables and graphs.

\section{Results and Discussion}

\section{Characteristics of Respondents}

Table 1 represents the participation of the respondents, most (63\%) of them were female. The middle-aged between 46-60 years was the most represented age group. Majority of respondents had acquired formal education (96\%) whereas $4 \%$ had not. Most respondents were involved in private companies followed by farming, own business, government service, job abroad and labor. Majority of the respondents $(59 \%)$ were native whereas $40.5 \%$ migrated in from different parts of the country. 


\section{Table 1 : Basic Characteristics of Respondents}

\begin{tabular}{|l|l|l|l|}
\hline Particulars & Group & Number & $\begin{array}{l}\text { of } \\
\text { Respondent }\end{array}$ \\
\hline Gender & Male & 74 & 37 \\
\hline & Female & 126 & 63 \\
\hline & & & \\
\hline Education & No formal education & 8 & 4 \\
\hline & Under SLC & 37 & 18.5 \\
\hline & SLC pass & 65 & 32.5 \\
\hline & Intermediate pass and above & 42 & 21 \\
\hline Age & $18-30$ & 44 & 22 \\
\hline & $31-45$ & 62 & 31 \\
\hline & $46-60$ & 73 & 36.5 \\
\hline & & & \\
\hline Occupational status & Government service & 34 & 17 \\
\hline & Private company & 56 & 28 \\
\hline & Own business & 40 & 20 \\
\hline & Farming & 41 & 20.5 \\
\hline & Abroad & 16 & 12. \\
\hline & Labor & 5 & 2.5 \\
\hline & & & \\
\hline Nature of residency & Native & 119 & 59.5 \\
\hline & Migrant & 81 & 40.5 \\
\hline
\end{tabular}

Figure 2 shows the distribution of respondents according to the number of trees they have on their properties. Majority of the respondents (29\%) had 1-5 trees

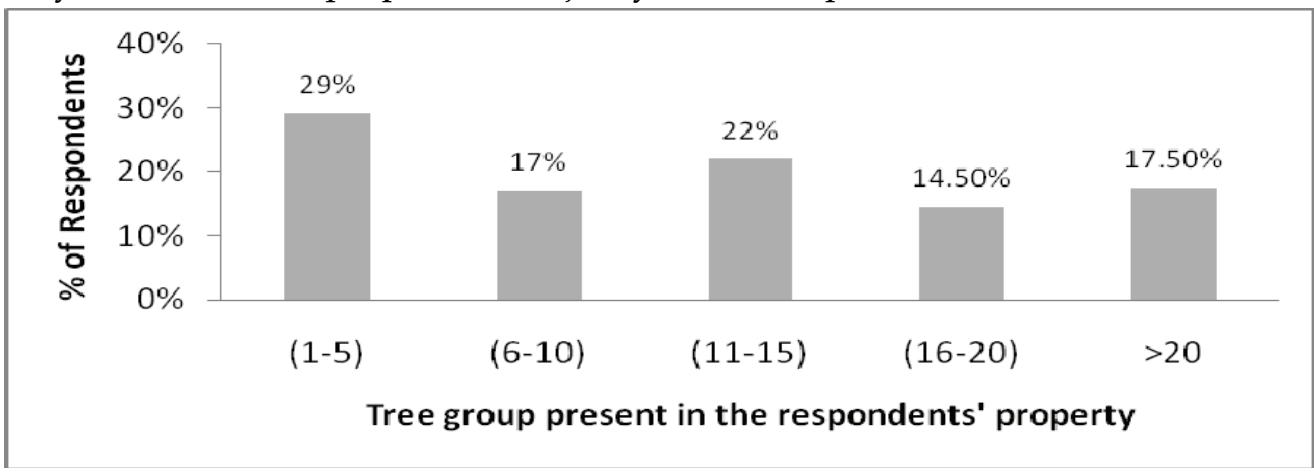

Figure 2 : Distribution of Trees on the Respondents' Property

and minority (17\%) had 6-10 trees. Majority of the respondents $(71.5 \%)$ had planted trees on their front yard property whereas $54 \%$ had in their back yard. Only few respondents $(4.5 \%)$ had trees maintained in their terrace. Variety of 
fruit trees like Psidium guajava, Mangifera indica, Litchi chinensis, Musa acuminata, Punica granatum, Prunus persica, Cocos nucifera, Persea americana, Phyllanthus emblica, Citrus limon, Nyctanthes arbortistis, Aegle marmelos and Carica papaya were found planted in pots/ground on the respondents' properties. The respondents were also found to be fond of various kinds of medicinal trees like Azadirachta indica, Piper cubeba, Ferula asafetida, Justicia adhatoda, Vitex negundo and Diploknema butyraceae as well as aesthetical trees/ plants like Hibiscus rosasinensis, Eurphorbia pulcherrima, Juniperus indica, Araucaria columnaris, Polyalthia longifolia and Areca catechu. Trees of religious values like Elaeocarpus ganitrus, Ficus religiosa and Pterocarpus santalinus were also found on their properties. Other species like Delonix regia, Albizia lebbeck, Bambusoideae, Bombax ceiba, Tectona grandis, Paulownia elongata, Olea europaea, Coffee, Cinnamomum tamala, Melia azedarach, Leucaena leucocephala and Bauhinia purpurea were also found planted on respondents' properties.

\section{Attitudes of Respondents towards Trees Established on their Property}

\section{Motives of Residents to Plant Trees on their Property}

Figure 3 shows that the most common motives of respondents to plant trees on their properties were for food $(76.5 \%)$, shade $(74 \%)$ and for medicinal purpose (71\%). The next common reason to plant trees was for aesthetical purpose for flowers, and to improve appearance of the house. It was interesting to find that some respondents (21\%) even had hobby of collecting unique trees. Since, Hinduism has a long lived tradition of worshiping deities in various forms of nature including trees, some respondents (15\%) had planted trees because of its' religious values, whereas some had planted trees because of their environmental values for improving quality of air, stabilizing soil and attracting birds. Very few respondents had planted trees for the social cause to commemorate a person $(1 \%)$, and because of the gift received (1.5\%). It suggests that respondents highly valued functional benefits of trees whereas social values were given less importance. 


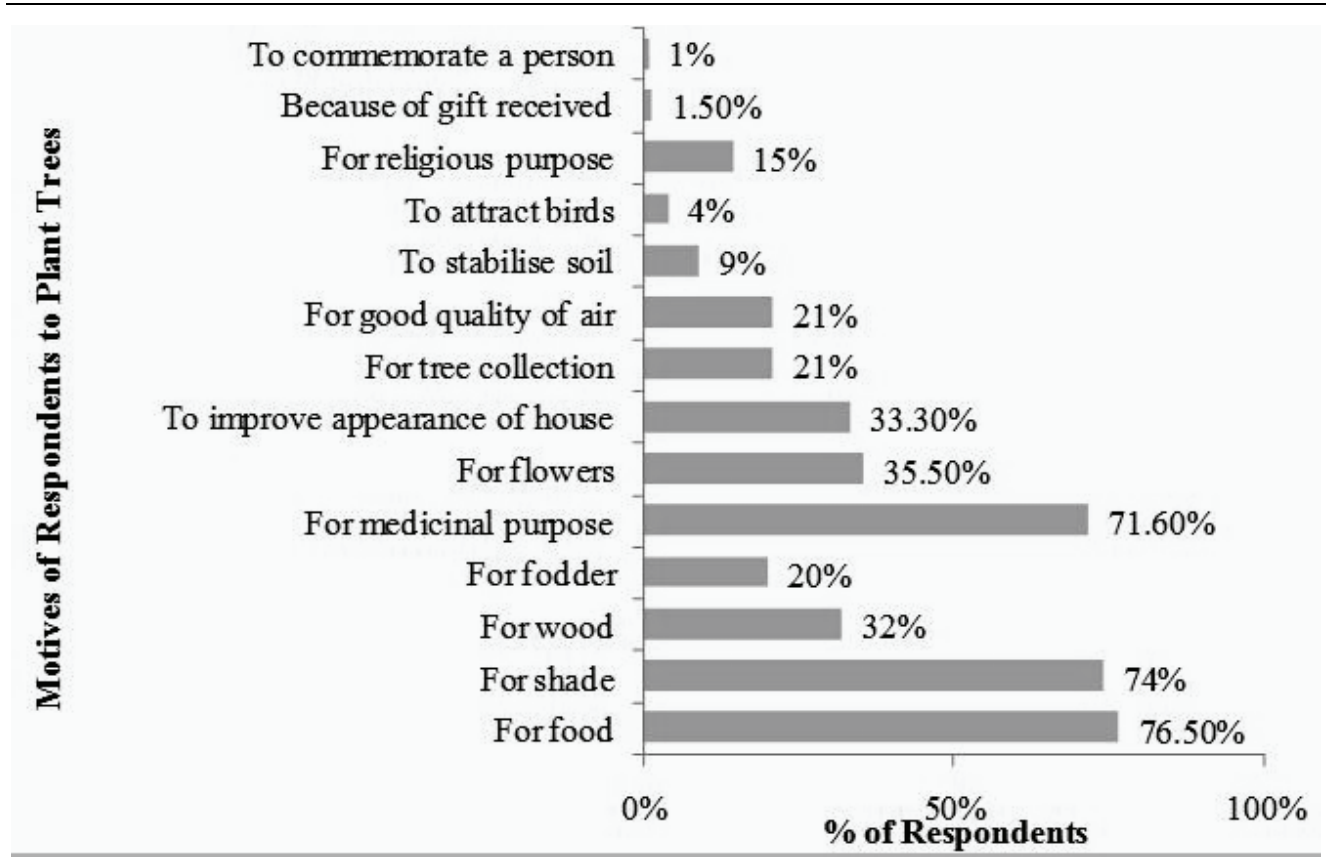

Figure 3 : Motives of Respondents to Plant Trees

\section{Analysis of Cognitive Component of Residents' Attitude}

Table 2 presents the cognitive component of the residents' attitude in which statements about tress were ranked according to the agreement level (strongly agree- 5 to strongly disagree- 1 ). Most of the respondents had positive cognitive intention towards trees, which is shown by the scores $(3<M \leq 5) .8$ out of 10 items measuring the cognitive components of respondents' attitude towards trees showed positive perceptions while 2 items showed low cognition $(M<3)$. The mean score of all the weighted means $(\mathrm{M}=3.882)$ showed that overall respondents had positive perceptions about urban trees.

The ranking of the items in the table indicates that the residents have high cognition towards the visible functional significances of trees whereas most of them were not cognizant of the environmental significances of trees. The statement 'Trees are important because they provide shade and cool their surroundings' was ranked third. However, the statement 'Urban trees help to reduce the energy use of buildings' was ranked the least. It suggests that even if the residents believed that trees are important because they provide shade, paradoxically, most of them didn't believe that trees help to reduce buildings' energy use. 
Table 2: Analysis of Cognition of Residents on the Importance of Trees

\begin{tabular}{|c|c|c|c|}
\hline SN & Items & $\begin{array}{l}\text { Weighted } \\
\text { Mean }\end{array}$ & $\begin{array}{l}\text { Standard } \\
\text { Deviation }\end{array}$ \\
\hline 1 & $\begin{array}{l}\text { Trees are important because they provide food } \\
\text { security. }\end{array}$ & 4.97 & 0.184 \\
\hline 2 & $\begin{array}{l}\text { Trees are important as they provide fuel wood } \\
\text { and timber. }\end{array}$ & 4.94 & 0.238 \\
\hline 3 & $\begin{array}{l}\text { Trees are important because they provide } \\
\text { shade and cool their surroundings. }\end{array}$ & 4.82 & 0.389 \\
\hline 4 & Trees help to improve health and quality of life. & 4.21 & 0.563 \\
\hline 5 & $\begin{array}{l}\text { Trees in cities help people feel better and less } \\
\text { stressed. }\end{array}$ & 3.99 & 0.53 \\
\hline 6 & Trees help to reduce the risk of flooding. & 3.86 & 0.492 \\
\hline 7 & Trees help to reduce environmental pollution. & 3.29 & 0.654 \\
\hline 8 & $\begin{array}{l}\text { Trees can play important part in reducing } \\
\text { climate change. }\end{array}$ & 3.18 & 0.475 \\
\hline 9 & $\begin{array}{l}\text { Trees should be planted in urban areas because } \\
\text { they reduce noise. }\end{array}$ & 2.96 & 0.352 \\
\hline 10 & $\begin{array}{l}\text { Urban trees help to reduce energy use of } \\
\text { buildings. }\end{array}$ & 2.6 & 0.903 \\
\hline
\end{tabular}

Mean score $=3.882$

Effects of Trees on Respondents' Properties and their Feelings towards the Effects (Affective component of residents' attitude)

Figure 4 demonstrates the effects of established trees on the respondents' properties. It showed that the positive effects of trees were highly rated than the annoyances associated with the trees. The most common positive effects of trees were food security, shade, clean and fresh air, and the most common negative effects were increase in number of bushes and weeds, wildlife hazards and risk of tree fall due to wind. It was also found that the same effects deemed as problematic or undesirable by some of the respondents were not problematic for others. $52 \%$ respondents said that the trees on their properties provided shelter for wildlife. Among them, 57.7\% favored the effect whereas others considered it as problematic. Respondents had faced problems due to wildlife, hornet attack, damage by birds, annoying noise of birds and snakes. It was interesting to find that most of the respondents favored their trees producing too much litter whereas only $14 \%$ disfavored the effect. Most respondents had taken benefits of this effect by utilizing the litter as manure in their garden. Only few respondents 
had faced the problem of power line disturbance and property damage due to trees.

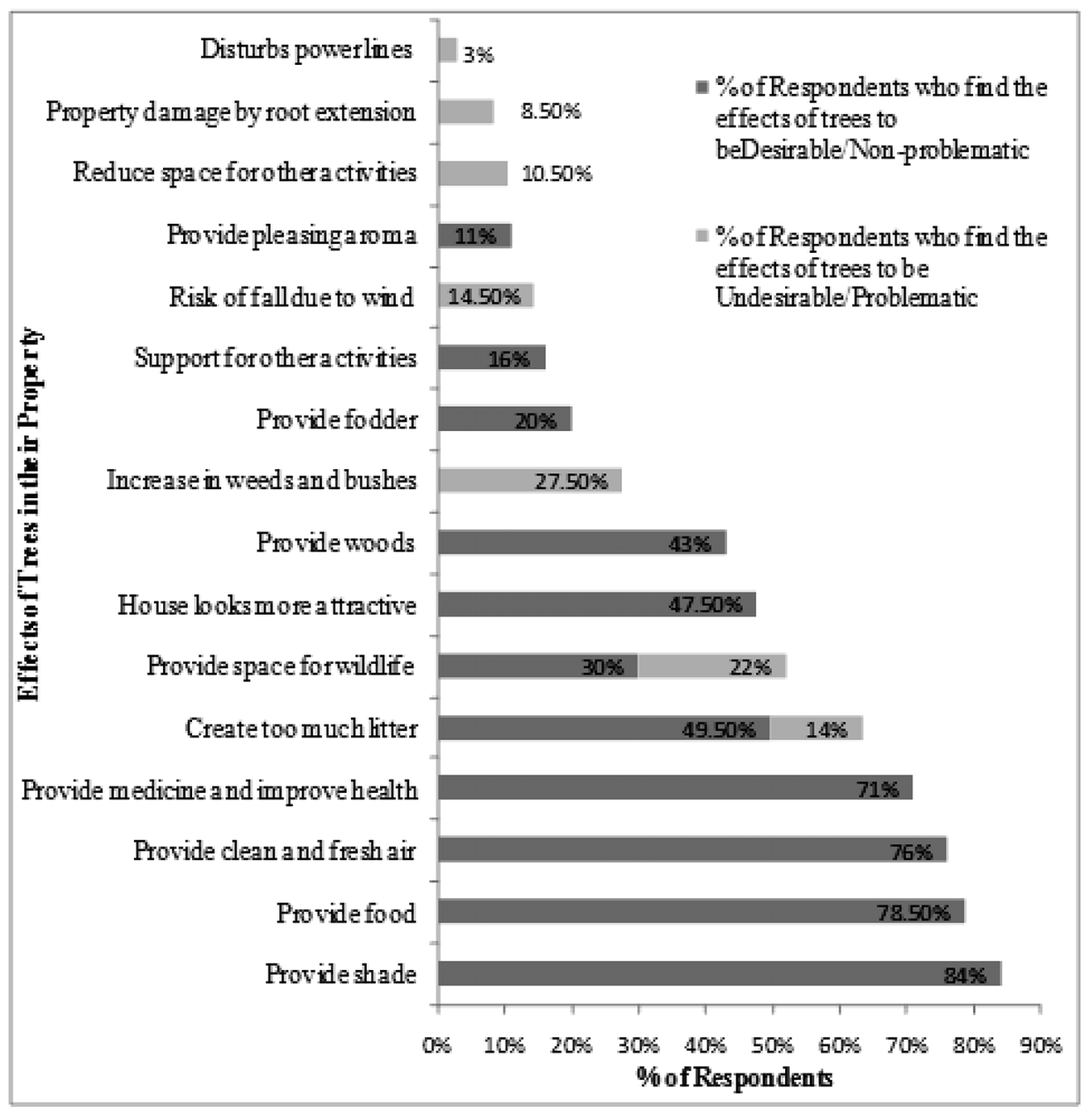

Figure 4 : Effects of Trees on the Respondents' Properties

Respondents' feelings towards the effects of trees on their properties are presented in Table 3. Most of the respondents $(51.5 \%)$ had positive feelings towards the effects of trees on their properties while 13.5\% felt that the trees had somewhat unpleasant effects whereas $8.5 \%$ had neutral feelings. Clearly, the residents perceived a strong connection with the effects of trees. 
Table 3 : Rating of the Effects of Trees on the Respondents' Properties

\begin{tabular}{|l|c|c|}
\hline Bipolar adjectives & Frequency & Percentage \\
\hline Very pleasant $(+)$ & 103 & $51.5 \%$ \\
\hline Somewhat pleasant $(+)$ & 53 & $26.5 \%$ \\
\hline Neutral(0) & 17 & $8.5 \%$ \\
\hline Somewhat unpleasant(-) & 27 & $13.5 \%$ \\
\hline Very unpleasant(-) & 0 & $0 \%$ \\
\hline Total & $\mathbf{2 0 0}$ & $\mathbf{1 0 0} \%$ \\
\hline
\end{tabular}

\section{Behavioral Intentions of Residents towards Trees on their Properties (Behavioral component of residents' attitude)}

Table 4 represents the behavioral intention of respondents towards trees on their properties. It was found that the majority of respondents had positive intentions towards trees. 'Positive' in the sense that most of them (45.5\%) showed their willingness to retain the existing trees without adding or removing any, add more trees in future $(29.5 \%)$ and replace the old trees with new ones $(14 \%)$. The respondents showed a high preference for adding more fruit trees in future, followed by medicinal, aesthetical and fodder trees while few respondents showed fondness for new types of species. However, $11 \%$ wanted to remove the existing trees from their properties without intending to plant any in future showing the negative behavioral intention towards trees. The most common reasons for intending to remove trees were the old age of trees $(24 \%)$, property damage (22\%), wildlife problems $(20 \%)$, increased number of bushes and weeds $(20 \%)$, the construction purpose $(16 \%)$, problems caused to neighbors $(14 \%)$ and disturbance to power line $(8 \%)$.

It suggests that many residents were unaware of the types of trees appropriate for planting on the residential properties and tree care and maintenance routines due to which they were negatively affected by the problems caused by trees. It is clear that their dissatisfaction towards the negative effects of trees influenced their intention to remove trees from their property in the future. 


\section{Table 4 : Behavioral Intention of Respondents towards Trees}

\begin{tabular}{lcc}
\hline Behavioral Intentions & Frequency & Percentage \\
\hline $\begin{array}{l}\text { Will neither add nor do remove trees in future } \\
\text { (retain the existing trees) (+) }\end{array}$ & 91 & $45.5 \%$ \\
Will add more trees in future (+) & 59 & $29.5 \%$ \\
Remove and replace with new trees(-) & 28 & $14 \%$ \\
Remove some/all the existing trees but will not & 22 & $11 \%$ \\
plant any in future. (-) & & \\
\hline Total & $\mathbf{2 0 0}$ & $\mathbf{1 0 0 \%}$ \\
\hline
\end{tabular}

\section{Tree Care and Maintenance Behavior of Respondents}

$73 \%$ respondents carried out pruning activities and $24.5 \%$ cleaning for the maintenance of trees in their yards. Of those who do pruning, $83.56 \%$ did the work themselves, and $16.44 \%$ hired an uncertified person. In terms of their intention for pruning, $56.16 \%$ respondents did so to maintain the shape of trees and $66.43 \%$ to remove dead or damaged wood. Many respondents (51\%) reported the difficulty in finding a good tree worker. Pruning work conducted by unqualified persons may be more likely to include arboricultural practices that are detrimental, such as topping. The importance of the professional expertise provided by certified, insured arborists is another public outreach opportunity.

The residents had positive attitudes towards urban trees on their properties, and believed that trees were important. Residents' belief about most of the benefits of the trees is consistent with other assessments of attitudes about urban trees. For example, Zhang et al. (2007) reported that $90 \%$ of respondents from Alabama appreciated urban trees in choosing their residential location and community. Similar conclusions were drawn in previous studies across various parts of the world (e.g. Kirkpatrick et al. 2013; Schroeder et al. 2006; Shackleton et al. 2015; Zhang, Zheng 2011). In case of Nepal, only few studies have been conducted in metropolitan cities related to urban forestry. For example, Lamichhane and Thapa (2012) reported that respondents from Chitwan and Pokhara agreed that the urban forests were useful for addressing the negative impacts of urbanization. Similarly, most respondents held positive attitudes towards urban forests, and were aware of the benefits provided in Lalitpur Metropolitan city (Gurung et al. 2012). Overall, there may be changing trends of urban people towards attractive and easily manageable tree species in their home yards and avenues. 


\section{Conclusion and Recommendations}

The study revealed that in Bharatpur Metropolitan city most residents had positive attitude towards trees as they had positive cognition regarding the significances of trees, and showed willingness to retain the existing trees and add more in future. Residents preferred highly valued trees, such as Psidium guajava, Azadirachta, Hibiscus rosasinensis, Elaeocarpus ganitrus and others for their functional benefits; mainly for food, medicinal properties and shade. However, very few were cognizant of the environmental values of trees, e.g. trees planted in urban areas reduced noise. Urban planners interested in influencing residents' decisions about residential trees need to work on public outreach. Residents need to be made aware of the long term and multi-functional benefits of trees to motivate them to retain existing trees on their properties. Residents should also be made aware of the type of trees that are suitable for plantation on residential properties to help them avoid the property damage due to trees during natural hazards. Since, most of the residents carry out pruning activities themselves, urban forest managers can develop and circulate pruning information among the residents through workshops with demonstrations of proper pruning techniques. The demand for the professional expertise provided by certified, insured arborists calls for another necessary public outreach. Future studies should expand at a national scale and identify geographic patterns of household attitude and behavior towards urban forestry across multiple scales.

\section{Literature Cited}

Bakrania, S. (2015): Urbanization and Urban Growth in Nepal. GSDRC Helpdesk Research Report 1294, GSDRC, University of Birmingham, Birmingham, UK.

Beckett, K.P., Freer-Smith, P.H., Taylor, G. (2000): The capture of particulate pollution by trees at five contrasting urban sites. Arboriculture Journal, 24:209-230.

Bharatpurmun.gov.np. (2019): Bharatpur Metropolitan City | Office of Municipal Executive, Bharatpur. [Online] Available at: http:/ /bharatpurmun.gov.np/en [Accessed 14 Mar. 2019].

Diley, J., Wolf, K. (2013): Home owner interactions with residential trees in urban areas. Scientific Journal of International Society of Arboriculture, 39(6): 267-277.

FAO. (2016): Guidelines on Urban and Peri-urban Forestry, by F. Salbitano, S. Borelli, M. Conigliaro and Y. Chen. FAO Forestry Paper No. 178. Food and Agriculture Organization of the United Nations, Rome. 
Goutam, K.R. (2018): Urban forestry in the federal context of Nepal. Banko Janakari, 28: 1-2.

Gurung, A., Karki, R., Bista, R. (2012): Peoples' Perception towards Urban Forestry and Institutional Involvement in Metropolitan Cities: A Survey of Lalitpur City in Nepal. Springer, 11, 193-205.

Lamichhane, D., Thapa, H.B. (2012): Participatory urban forestry in Nepal: Gaps and ways forward. Urban Forestry \& Urban Greening, 11: 105-111.

Jain, V. (2014): Attitude: Triode Approach. International Journal of Advanced Research in Management and Social Sciences, 3(3): 1-12.

Kirkpatrick, J.B., Davison, A., Daniels, G.D. (2013): Sinners, scapegoats or fashion victims? Understanding the deaths of trees in the green city. Geoforum, 48: 165-176.

McPherson, E.G., Simpson, J.R., Peper, P.J., Xiao, Q. (1999): Benefit-cost analysis of Modesto's municipal urban forest. Journal of Arboriculture, 25: 235-248.

MFALD. (2019): Environment-friendly Local Governance Framework, 2013. Ministry of Federal Affairs and Local Development, Government of Nepal, Kathmandu.

Schroeder, H., Flannigan, J., Coles, R. (2006): Residents' attitudes towards street trees in the UK and U.S. communities. Arboriculture and Urban Forestry, 32(5): 236-246.

Shackleton, S., Chinyimba, A., Hebinck, P., Shackleton, C., Kaoma, H. (2015): Multiple benefits and values of trees in urban landscapes in two towns in northern South Africa. Landscape and Urban Planning, 136: 76-86.

UNDESA. (2019): 2018 Revision World Urbanization Prospects. United Nations, Department of Economic and Social Affairs, New York.

Zhang, Y., Hussain, A., Deng, J., Letson, N. (2007): Public attitudes towards urban trees and supporting urban tree programs. Environment and Behaviour, 39(6): 797-814.

Zhang, Y., Zheng, B. (2011): Assessments of citizen willingness to support urban forestry: An empirical study in Alabama. Arboriculture and Urban Forestry, 37(3): 118-125. 